\title{
Epistemology of the New Social Movements in the International System and Middle East
}

\author{
Havva Ebrahimipour \\ PhD student of Department of Political Sciences, University of Isfahan, Iran \\ Email:h.ebrahimipour@yahoo.com

\section{Seyyed Javad Emam Jome'zadeh} \\ Associate professor of Department of Political Sciences, University of Isfahan, Iran \\ Email:javademam@yahoo.com

\section{Hossein Masoudnia} \\ Assistant professor of Department of Political Sciences, University of Isfahan, Iran \\ Email: hmass2005@yahoo.co
}

\section{Doi:10.5901/mjss.2015.v6n5s1p319}

\section{Abstract}

From 2010 onwards, the international system has observed public protests providing the situation for entering a new level of political and social evolutions around the world and the region. The transition from collective action based on class to action based on notions of identity, transition from unilateralism in action to interactive model and relationship-based and transition from economic aims in the form of collective action to symbolic cultural and political aims have been the main elements of evolution of social movement in the recent years. The current article is a response to the reason of incidence of such evolution and why the pluralism and increased access of people to political procedures, development of information and communication technologies, and highlighting the role of civil society, non-governmental organizations and expansion of role of new middle class have resulted in such evolution. Discussions made by authors such as Alberto Melucci regarding the interactive and identity-based action, could be appropriate theoretical frameworks for surveying the process of transition from conventional social movement to new social movement (NSM). From the point of research condition, the current article is a descriptiveanalytical survey and from the point of aim it is an applied survey.

Keywords: Social Movement, Identity Action, Cognitive Needs, Melucci, Interactive Approach, New Social Environment.

\section{Introduction}

The concept of social movement is one of the concepts in the field of social and political sciences that do not have a single definition; thus the same as many other concepts of this field it does not describe a part of the reality; rather it is an element of a specific method of constructing the social reality. Existence of social movements as a part of social and political life of western countries, especially during the modern times has turned into a rather ordinary phenomenon. During the last decades, western and non-western societies have continuously encountered many social movements such as Peasant Movement, Labor Movement, Syndicalist Movement, Islamist Movement, Anti-Colonial Movement, Women Movement and Resistance Movement. In other words, in the postindustrial society, in contrast to the industrial society in which production and reproduction of sense of collective identity and solidarity was facilitated by closeness of workplaces and living place, this sense is less based on the direct and face-to-face interactions developed in the daily traditional and local society.

On the other hand, in the age of globalization, due to the existence of media, the territory of social relationships of human beings has tremendously expanded and each individual is linked with social groups and different groups in a communication network and these vast communications and numerous belonging to groups have become a base for producing and reproducing multiple and hybrid identities. Globalization of communications has resulted in formation of a new type of social movement. Although in terms of central role of civil society these new movements are in common with classic social movements, in functionality the identity and in evolution the leadership and organization are completely different from the previous social movements. New social media act differently based on the features of social 
environment and expressing themselves and this affects the dynamism of public movements. Encouraging and motivating the protestors under the influence of social networks take form through distributing information among individuals and friends with this advantage that audience are interested in these resources and trust them. The growth of internet especially in western world had an effect on many variables such as communication, politics, participation and public opinion.

The current article question is that what are the components and concepts of social movements and what are the functions of the social movements? What are the reasons for evolution of social movements from industrial (conventional) society to postindustrial (new) society? And based on what conceptual model it is possible to explain and analyze the new social movements in the international and regional level.

\section{Theoretical Framework}

Alberto Melucci interactive-Identity theory is a theory that describes the collective processes and their role in the transformation of society with emphasis on the political and cultural factors. On the other hand, due to the changing nature of social protests with an emphasis on identity-based social movement, believe that the Melucci Identity theory can be a useful framework for understanding how and why an entity these changes in the international system and the Middle East. Melucci is a scholar considered to belong to the Marxism family who proposed identity-oriented action paradigm and changed the center of attention from focusing on work-capital factor (production field), to interaction and communication field including factors such as personal identity, gender, method and quality of life. Explaining the theory, Melucci emphasizes that being a new concept is relative and in terms of contemporary movements it indicates a number of relative differences among historical forms of class, class conflicts and new forms of action in the contemporary societies. In contrast to other theorists of social movement, Melucci looks for explaining the reason of movements in societies (why) and looks for explaining how the social movements form in a society (how). In this regard Melucci believes that the collective action must be considered as a product not an origin. The central concept in Melucci's discussion as an interaction is the concept of collective identity. In this relation Melucci states that the individual and cognitive needs formed from these needs are combined with environmental conditions and these three concepts are considered as three poles of social movements and as a result they form a collective identity and this collective identity is in fact the communicational factor among individuals (Melucci, 1989: 34). In Melucci's theory, collective identity is considered as the main element of collective actions. Collective identity is the mutual and produced definition of interactions among a few individuals communicating with each other and paying attention to their actions, the facilities and limitations in which their actions take place (Melucci, 1989: 34). Melucci believes that NSMs are the confluence of collective participation and individual conflicts. These movements are cause by creating a new sense of finding power and enhancing "self" originated from collective action; in other words, action happens as a result of a relatively constant and combined collective identity, an "us" that must be created from aims, tools and different types of solidarity and organization. For explaining this relation between collective identity and collective action, Melucci states that identity is neither an independent subject nor a feature of social actors, rather Melucci defines identity as a process through which the social actors organize themselves and become organized as a part of larger groups by the other actors. Based on such loyalties, individuals give meanings to their experiences and progresses during time and in other words, through producing, protecting and restoring identities, individuals define and redefine the individual projects and create or eliminate the possibilities of actions. Melucci emphasizes that identities are usually political and personal processes in which we participate. Identity formation could not be solely reduced to mental mechanisms and it is rather a social process and a rediscovery of "self" through collective processes (Melucci, 1989: 42-43).

\subsection{Ontology of Evolution}

A) Changing the nature of protests: Since the conventional social movements had an ideology-driven nature emphasizing on Marxist conception of ideology as an element of unity and integrity-orientation for collective action, and programs were designed for improving the dissatisfactions and finding their reasons, these formed the ideological foundation of mobility (Esmlser, 1962: 20); whereas NSMs show plurality of values and believes lacking a hierarchical attitude, having an anti-ideological view tending toward pragmatic orientation and searching for fundamental reforms expanding the systems of member participation in decision makings. These movements have important political meanings in western societies; they guarantee the meaning of dynamism toward democratization of everyday life and expanding the civil aspects against political aspects (Larna \& et al, 1998: 20-22). 
B) Changing the political appearance of protests: NSMs lack hierarchical attitude and have anti-ideological view; whereas conventional social movements had hierarchical structure and did their activities in the form of a party (Nash, 2003: 145-146). NSMs mainly act through networks for creating a link and association between the collective and non-private actors and other movements worldwide and they are less hierarchical and they usually have open and flexible structure; whereas, their conventional types have more network intergroup and inter-movement characteristics rather intra-movements (Sardarnia, 2009: 5-6). NSMs have an open, current and flexible organization and they have active and maximum participation. In relation to appearance of forces in NSMs, Larna believes that unlike centralized bureaucracies and directors of mass political parties, NSMs tend to do their activities part by part, decentralized and dispersed (Larna, 1998: 21). Mainly, the conventional movements were hostile; whereas NSMs are peaceful and have less hostility (Kaldor, 2003: 83).

C) Changing the aims of protests: The aim of conventional social movements was universal transformation of the society. Changes these movements were looking for were rapid, great and usually hostile changes; and they were mostly categorized in transformational movements (Cohen, 2004: 406). In this regard Scott believes that conventional social movements were looking for a type of merger whereas the NSMs are looking for defending from free public sector, expanding civil rights, and creating a rational government through minimizing the social inequalities in the civil society in order to expand the government's accountability to rational decision making (Scott, 1990: 72-78).

Change of actors of the protests: Replacing the working class which was formerly considered as the broker of revolutionary change with the intellectuals, university students, women and new jobs is one of the main differences of NSMs compared to the conventional social movements (Touraine, 1981: 61). Regarding the mentioned changes, nowadays we globally observe the emersion of NSMs with titles such as Culture- centered (non-political) Social Movements, Identity- oriented Social Movements, Network- oriented Social Movements, Integration- centered Social Movements and Pluralism-oriented Social Movements (due to existence of different actors with meta-class nature). Next paying attention to the reason of occurrence of these changes is also informative and helpful.

\subsection{Epistemology of Evolution}

A) Development of information and communication technologies: The first factor for making a change and evolution in social movements is developing the information and communication technologies. By the increasing progress of mass media instruments around the world and possibility of access to the latest news and reports from the farthest places in the world and optimal use of media and hypermedia, these communicational tools provide the base for occurrence of evolutions inside the countries along with affecting the international system. Achievement made by the scientific revolution and new digital technologies especially in the field of communications, has provided an opportunity for emersion of social forces, institutions and networks inside the countries. The internet as the most important phenomenon of information and communication technologies in one hand results in fading national borders and reducing the power of governments and especially the authoritarian governments and on the other hand it results in expanding and reducing the distance between human beings in different societies.

B) Highlighted role of civil societies, expanding the role of new middle class: Regarding the second reason of occurrence of NSMs, Offe states the emphasis on changing the class structure of advanced capitalist societies and evolution of the society from industrial modernity to post modernity and post-industrialism which ultimately resulted in relative prosperity of social democracy, high level of education and growth of service sector (Offe, 1987: 77). By the occurrence of globalization phenomenon, the primary base of global civil society has been provided and it is developing regarding the significant speed in the developed world and to some extent in the developing world. NSMs and non-governmental organizations (NGOs) whether nationally or internationally are the important components and actors of the civil society. Also, in the new era we observe the interactive approach between governments and civil society in both land-national and global fields (Sardarnia, 2009: 2).

\section{Conclusion}

Other important notes that must be taken into account as a result of evolution of conventional social movements to NSMs are the important role of people and the importance of public opinion in the political and social arena. At the current time, as a result of current movements, we observe the direct confrontation of people with the government structure outside the party, organizational and bureaucratic events; people who confront authorities pursuing new aims different from the past 
without having a party or charismatic leader and they have shown that they have the power to make a change; and this has resulted in enhancing the civil society, accepting the plurality of values and ideals and being unified in the form of a collective identity. For instance, in terms of identity, the relation between religion and politics in the Middle East and North Africa is more visible than other parts of the world and one of the most important factors making internal and external policies in this region is the religious identity. On the other hand, religious identity-orientation is linked with signs such as political participation of social groups. Due to this, the social movements of a region not only have an anti-dictatorship nature, but also are linked with aspects of religious literature. In such process, the concepts of freedom, democracy, spirituality and justice form a link; thus identity-orientation is an inevitable part of political and social changes of a region or the world.

\section{References}

Cohen B, (2004). Concepts of sociology. Translated by Tavassoli GHA and Fazel R, Samt Publications.

Della porta \& Diani Mario (2006). Social Movements an Introduction, second edition, Oxford:Blackwell Publishers.

Melucci, A(1985) The Symbolic Challenges of Contemporary Movements, Social Research, Learning52.

Melucci, A(1988), Getting Involved: Identity and Mobilization in Social Movements, in B Kladermans,H. Kriest, and S. Tarrow(eds), From Structure to Action: Comparing Social Movement Research across Cultures, JAI press:Greenwich,Connecticut.

Melucci, A(1989) Nomads of the Present: Social Movements and Individual Needs In Contemporary Society, London,.Hutchinson Press. Melucci, A(1995). The Process of Collective Identity. Temple University Press

Nash K, (2003). Contemporary political sociology: globalization, politics and power. Translated by Delforouz MT, Tehran: Kavir Publicatios.

Offe, Claus(1985), New Social Movements: Challenging the Boundaries of Institutional Reform, Telos, 52.

Sardarnia KHA, (2009). Internet, NSMs and mobility of protests: theoretical and exemplary survey of a few social movements. Communicational researches. $16^{\text {th }}$ year, No. 4.

Smelser, Neil(1963), Theory of Collective Behaviour, New York, Free press. 